\title{
Intention AND the Basis of MeAning
}

\author{
RAY BUCHANAN \\ University of Texas at Austin
}

1.

As is well known, Grice and his followers hold that speaker meaning is fundamentally a matter of intention. ${ }^{1}$ More specifically, they hold that the sense of 'means' relevant to claims such as (1)-(3) must be analyzed in terms of an agent's audience-directed, communicative intentions:

(1) By pointing to the door, Carla meant that Rosa should leave.

(2) Rosa meant that she was not ready to leave the party by uttering 'Not yet'.

(3) By uttering 'Some students passed', Oscar meant that not all of his students in Logic 101 passed.

Though Griceans might disagree on the details, they are united in holding that in those cases in which an agent performs an action $\Phi$-linguistic, or otherwisewith a particular audience A in mind, she means something by $\Phi$ only if the following conditions obtain:

(Grice) S means something by $\Phi$-ing only if, for some audience A, S $\Phi$-ed intending, (i) to produce a certain response in $\mathrm{A}$, and (ii) for A to recognize (i), at least in part, on the basis of the fact she $\Phi$-ed. ${ }^{2}$

1. See Grice (1957; 1969). Hereafter, I'll use "speaker meaning", or sometimes simply "meaning", for the sense of 'means' relevant to an agent's meaning something by an action (as opposed to the sense of 'meaning' applicable to linguistic expressions, non-linguistic conventional signals, and 'natural' signs or indicators).

2. The restriction to cases in which the agent has a particular audience in mind is to help us avoid complications involving 'audience-less' cases (think, e.g., of a Robinson Crusoe in soliloquy). The standard Gricean responses to such cases will not ultimately help with the examples I'll give below as they concern speakers with specific audiences in mind with whom they are genuinely seeking to communicate.

Contact: Ray Buchanan <raybuchanan@mail.utexas.edu> 
In the special case in which a speaker means that $p$, some Griceans hold that the relevant intended response must be to bring about, or activate, in A the belief that $p$; whereas others might require that $\mathrm{S}$ intend that $\mathrm{A}$ take her $(\mathrm{S})$ to believe that $p$. All Griceans will agree, however, that an agent must (minimally) intend for her audience to entertain that $p$ in those cases where she means that $p$ by $\Phi$-ing.

The post-Grice literature on the prospects for an analysis of meaning is vast and notoriously complex. As the later efforts of Grice, Schiffer, and others have made clear, it is exceptionally difficult to see how - and, for that matter, whetherthe foregoing conditions in (Grice) might be elevated into a full-fledged analysis of speaker meaning. ${ }^{3}$ But despite these difficulties, it is still, as Lycan puts it, 'generally assumed that speaker meaning must in some way be a matter of intention and other mental states' (2008: 92). The consensus view is that audience-directed intentions of the foregoing sort are at least necessary for an act of meaning.

In what follows, I argue that if intentions are what Grice, and most contemporary action theorists, take them to be, they are inessential for acts of speaker meaning. More specifically, my primary aim is to show that the consensus view of speaker meaning is in deep tension with certain plausible, and widely accepted, cognitive constraints on rational intention pertaining to an agent's assessment of her prospects of achieving her goal. My secondary aim is to offer an initial case for thinking that the best way to resolve this tension is to give up (Grice), and with it the claim that meaning is fundamentally a matter of intention. In pursuing this strategy, we will see some of the potential benefits of Bratman's (1987) work on intentions, plans, and practical reasoning for the theory of meaning, including some interesting consequences of his rejection of the socalled 'Simple View' on which we intentionally do only those things that we specifically intend to do. Moreover, our discussion will help to illustrate how some familiar tools from decision theory might find new use in discussions of meaning and communication.

2.

A rationally-formed intention-be it an intention to go to the store, to move one's arm, or to convey some information - is subject to certain cognitive constraints that acts of speaker meaning are not. Though there has been much debate re-

3. Griceans have traditionally sought to supplement (Grice) with numerous further conditions in the hopes of achieving both necessary and sufficient grounds for speaker meaning. For the most well worked out attempt at spelling out the details see Schiffer (1972) and (1982). Schiffer himself ultimately came to hold that no Gricean analysis, or explication, of speaker meaning is possible; see, e.g., the final chapter of Schiffer (1987) and the more recent Schiffer (2017) reply to Avramides (2017) for some of his reasons for despair. 
garding the interconnections between belief and intention it is uncontroversial that rationally intending to $\Phi$ is incompatible with an outright belief that one will fail to $\Phi$ :

(Constraint) S cannot rationally intend to $\Phi$ and at the same time believe that she will fail in her attempt. 4

Notice that a literal utterance of (4) clearly implies (5), and this is implication is no mere suggestion, or pragmatic implicature:

(4) Carla intends to pronounce 'Sartre' correctly, rolling the first $r$.

(5) Carla lacks the belief she will fail to pronounce 'Sartre' correctly.

Any attempt to cancel the putative conversational implicature - as in (6)-would suggest gross linguistic or conceptual incompetence with 'intends', or else irrationality on the part of the agent to whom the intention is ascribed:

(6) Carla intends to pronounce 'Sartre' correctly, but she believes that she will fail to do so.

If Carla actually had the combination of attitudes in (6), she would be no more rational than someone who intends to win the lottery by buying a single ticket even though, being fully aware of the million-to-one odds against success, actively believes that the ticket she will buy is a loser.

As Bratman (1987) and others have argued, a rational agent's intentions ought to be logically consistent with the totality of her beliefs. Following Ross (2009), we might precisify this requirement on practical reasoning as below, where we assume (for simplicity) that the propositional content of $S^{\prime}$ s intention to $\Phi$ is the proposition that $S \Phi^{\prime}$ s.

(Consistency) S ought rationally to be such that the intersection of the set of the propositional contents of S's beliefs and the set of the propositional contents of $S^{\prime}$ s intentions is logically consistent.

4. The belief/desire-based analysis of intention offered in Sinhababu (2013) is the only account of intention of which I am aware that is compatible with the falsity of (Constraint). Though I reject Sinhababu's account of intention, in part for this reason, I am ultimately (as will emerge) very sympathetic to his emphasis on the fundamental role of desire in the story of intentional action. See García-Carpintero (2016) for an appeal to Sinhababu's account in connection with speaker meaning and communication. 
If it were possible for an agent to rationally intend to $\Phi$, while believing she will fail to do so, counterexamples to (Consistency) would be forthcoming. But insofar as there are no plausible counter-examples to (Consistency) (or so it is argued), we have extremely good further reason to accept (Constraint).

Likewise, consider the so-called mean-ends constraint on practical reasoning (again borrowing a formulation from Ross 2009):

(Means-End) S ought rationally to be such that (if she intends to $\Psi$ and she believes that $\Phi$-ing is a necessary means to $\Psi$-ing, then she intends to $\Phi)$.

If (Constraint) were false, it would be easy to construct counterexamples to (Means-End). After all, in a (putative) case in which an agent forms an intention to $\Phi$ that they believe they will fail to execute, what rational pressure could there be in forming further intentions to do those things they believe necessary for $\Phi$-ing? For example, if Oscar were (somehow) to form an intention, say, to pick up a friend from the airport while actively believing he will fail to execute that intention, why should he bother to form the intention to get off the couch, to get in his car, and so on? Insofar as (Means-End) is plausible, so too is (Constraint).

Notice that one can, and should, adopt (Constraint) even if one is skeptical that require accounts of stronger cognitive constraints on intentions. ${ }^{5}$ For example, in 'Intention and Uncertainty' (1971), Grice himself argued that when 'intends' is used in its strict and literal sense, $S$ intends to $\Phi$ just in case $S$ believes she will $\Phi$ as a more-or less, direct result of her willing to do so. Whereas Grice held this thesis as an account of intention simpliciter, other theorists with cognitivist leanings might accept this constraint only holds if it restricted to rationally formed intentions (I myself am sympathetic to this suggestion.) Likewise, even if you think that, for example, the relevant constraint is merely that $S$ must believe that it is more likely than not that she will $\Phi$ in order to intend to $\Phi$, you should still accept (Constraint).

Before turning to the issue of how these considerations regarding (rational) intentions interact with (Grice), let me mention one final point about the relationship between belief and credence that will be relevant. It is widely held, and we will assume in what follows, that rational belief is compatible with a credence that falls short of certainty. For example, even if one believes, say, that it will rain tomorrow, one might also rationally have a non-negligible credence that it will not rain. In connection with (Constraint) above, notice that this point leaves open the possibility that a rational agent who outright believes that she will fail in her

5. See, e.g., Grice (1971), Velleman (1989), Harman (1976) for more on this more demanding cognitive constraint on intention. 
efforts to $\Phi$ might, nevertheless, be less than fully certain that she will not fail to $\Phi$; an outright belief in failure need not itself foreclose on, by the agent's lights, the possibility of success.

\section{3.}

(Grice) taken together with (Constraint) entails that a rational speaker who utters $u$ and thereby means that $p$ cannot at the same time believe that she will fail in getting her audience to entertain that $p$. This entailment is false, and, hence, so too is the conjunction of (Grice) and (Constraint).

Assuming the foregoing point regarding the relationship between belief and certainty, it is a straightforward matter to construct counterexamples to the conjunction of (Grice) and (Constraint). Indeed, in any case in which a speaker believes, but is not certain, that her audience will fail to entertain that $p$ on the basis of her communicative efforts, she might, nevertheless, rationally mean that $p$, provided she has enough to gain and little enough to lose by trying.

Consider two illustrative cases:

Case 1: Imagine that Rosa-Linda has found herself in a mid-size Russian city and that someone at the hostel she is staying at has stolen her favorite derby hat. Later in the afternoon, Rosa-Linda is strolling about the city center where, in the distance, she spots someone in the distance wearing her beloved hat. Though she is highly confident, on the basis of very strong evidence (from guidebooks, etc.), that no one one within earshot speaks English, she yells out (7), as she knows no Russian, or any other language more likely to be spoken thereabout:

(7) He stole my derby!

She utters (7) because she wants her audience to entertain a proposition regarding the specific individual to the effect that he stole her hat. Even though she believed that she would fail in her communicative efforts, she wasn't certain that she would; there was, by her lights, at least the chance that she'd be understood. Given how much she had to gain, and little she had to lose, by expending the effort, she uttered (7) in the hope that someone near might understand. ${ }^{6}$

6. One can, of course, hope that $p$ will be the case even if one believes that $p$ will not be the case (e.g., I believe that my lottery ticket won't win, but I hope that it will). Moreover, one might rationally act on such a hope-even if one's credence in success is low-if the expected utility of so acting is sufficiently high. 
Case 2: On their first date, Carla and Oscar go to the local museum of modern art. After looking at thousands of different pieces, Carla- an avid art enthusiastwants to test Oscar. Of all of the pieces that they saw, one particularly challenging piece was a large abstract painting by Barnett Newman that consists of two blue fields of different intensity separated by a thin vertical orange line. Carla utters (8) to Oscar with the aim of getting him to entertain that the particular piece by Barnett Newman was her favorite:

(8) My favorite piece was the study of the relationship between foreground and background.

Carla thinks that the odds that Oscar will successfully recognize her efforts to get him to entertain that the Barnett Newman piece was her favorite piece in the gallery are exceedingly slim and for that reason believes that he will fail to understand her. Nevertheless, she utters (8) in the hopes that she might be wrong on this score. On the (by her lights) exceedingly slim chance that he recognizes her aim, she'd agree to go on second date. She produces her utterance with a communicative goal that she believes will not be fulfilled. ${ }^{7}$

I submit (i) that by uttering (7), Rosa-Linda meant that the particular individual stole her hat, and (ii) that Carla (indirectly) meant, or implicated, that the piece by Barnett Newman was her favorite by saying (8). In each case, should the speaker's audience have failed to entertain the relevant proposition, they'd have

7. Two quick points on these cases: First, I am not assuming that the agent's high level of credence that she will fail to be understood itself constitutes, or makes it the case that, she outright believes that she will fail. Though I am sympathetic to so-called Lockean accounts of the relation between credence and belief, I am not assuming such a view here (see, e.g., Sturgeon 2008). Rather, all I am assuming is, in effect, a kind of fallibilism about belief; a fallibilism that allows that a rational agent might believe that $\mathrm{p}$ while acknowledging the possibility that she might be wrong. While Fallibilism about knowledge is controversial, Fallibilism about belief should not be.

Second, as an anonymous referee has pointed out to me, some theorists hold that in certain "high stakes" scenarios, a rational agent might fail to form the outright belief that $p$ even if she has a high level of credence that $p$, if the cost of getting it wrong (i.e., falsely believing that $\mathrm{p}$ ) is sufficiently high. A theorist sympathetic to this line might then claim that, for example, in Case 1, Rosa-Linda merely has a high level of credence that she won't be understood, but does not outright believe this given the potential costs of her being wrong on that score. But notice that even if we wanted to take on board this stakes-sensitivity (and I am not convinced that we should) it is easy to construct variants on Cases 1 and 2 in which we simply lower the stakes of the speaker's being wrong on whether they'll be understood or not, so as not to (putatively) block the formation of the outright belief in failure. Imagine, for example, a version of Case 2, in which Carla is almost, but not fully, indifferent regarding whether she is understood by Oscar and that the stakes in her being wrong are quite low. Even if she outright believes that she will fail to be understood, expending the communicative effort in uttering (8) might nevertheless still maximize expected utility as she has a little more to gain than to lose by trying. 
failed to understand her and her utterance. Moreover, these speakers would be understood only if the audience indeed came to entertain the relevant proposition at least in part on the basis of the speaker's utterance.

In both of the foregoing cases, the agent might fully expect that her audience will recognize her utterance as a bit of intentionally produced evidence of a given communicative aim, even though she believes that her audience will not be in a position to infer from that evidence what exactly that aim consists in. With this in mind, a slightly different class of counterexamples can be constructed by tweaking the foregoing scenario with regards to the reasons for which the speaker believes her efforts will fail. Imagine, for example, a variation of Case 1 in which Rosa-Linda is instead in a small American suburb surrounded by numerous people, most of which she believes able to speak (and comprehend) English. Suppose that she has no doubt whatsoever that if her audience were to recognize that she produced the sentence 'The thief is getting away', they would quickly and easily infer that she had the communicative aim of getting them to entertain that the thief is escaping. But, further suppose that for whatever reason she also believes that either (i) she will not be able to successfully produce the relevant utterance (e.g., she's almost lost her voice from illness), or (ii) that the audience will not be in a position to recognize that she uttered the relevant sentence (e.g., she thinks they might be almost out of earshot). Nevertheless, given that she has so much to gain, and so little to lose, she tries anyway. Even if her production is exceedingly faint, or her audience is indeed just a little too far away, she'll nevertheless have performed an act of speaker meaning despite believing that her communicative efforts will fail.

In each of the foregoing cases, the speaker indeed acts with the aim or purpose of getting her respective audience to entertain a particular proposition. But if (Constraint) is correct, this alone does not suffice for them to so intend, as they actively believe that they will fail in their efforts. ${ }^{8}$ Notice, however, that believing that one's efforts will fail does not yet make for irrationality in the appropriate practical contexts - that is, one in which the speaker stands to gain a considerable amount, and little to lose, by their endeavor. In each of the foregoing cases, the potential payoff for their efforts being recognized far outweighs any potential cost of the speaker's efforts. By analogy, consider the quarterback who successfully throws the last-second, game winning 8o-yard Hail Mary touchdown pass. Even if he acts in the belief he will fail in his efforts, and hence does not act

8. In these cases, it might be claimed that the agent acts in the belief that her efforts might be successful. For present purposes, I have no objection to this suggestion so long as believing might $p$ is understood as rationally consistent with outright believing that not $p$. This possibility should be unproblematic if there are cases in which an agent's credence with respect to not- $p$ is sufficiently high to rationalize (or, perhaps constitute) her outright belief to that effect, but her non-zero credence in $p$ is sufficiently high to rationalize her believing might $p$. 
on an intention to score the touchdown, he is not for that reason irrational, nor is his throwing the touchdown unintentional. Our examples above are, in effect, "communicative Hail Marys" in which the speaker's efforts to convey the relevant information to her audience would seem perfectly rational insofar as they maximize her expected utility.

If the foregoing cases are indeed examples of speaker meaning, then we ought to reject either (Grice) or (Constraint). More generally, if intentions are what most action theorists take them to be (i.e., subject to (Constraint)), they are inessential for acts of speaker meaning.

\section{4 .}

Faced with the choice of having to choose between (Grice) and (Constraint), my own preference is to give up the former. For one thing, (Constraint) is, by my lights, more intuitively plausible than (Grice); instances of (Constraint) seem to me to be something akin to indefeasible, analytic truths. ${ }^{9}$ And second, as should already be clear, denying (Constraint) or replacing it with anything weaker would also call into question rationality constraints on intentions such as (Consistency) and (Means-End) above. For example, suppose (as is natural in light of the cases we've considered so far) that we were to drop (Constraint) in favor of the following weaker principle:

(Weak-Constraint) S can rationally intend to $\Phi$ only if she believes there is a possibility, however remote or miniscule, of her successfully $\Phi$-ing. ${ }^{10}$

9. To reiterate, (Constraint) only concerns rationally formed intentions. Hence, I am not denying that, in some cases, an agent might have an intention to $\Phi$ despite believing that she will not $\Phi$. Our quarterback in the Hail Mary case might truly volunteer that he intended to score the touchdown despite believing he'd fail to do so. What I'd deny, however, is that such an agent is rational. In other words, I am claiming that if we restrict our attention to rational agents, then instances of 'S intends to $\Phi$ at $\mathrm{t}$, but believes that, at $\mathrm{t}$, she will fail to $\Phi$ ' are analytically false. Even with this restriction in mind, I am aware that others might have differing intuitions on these matters. As such, I put more weight on the two additional considerations offered below in the text. Thanks to an anonymous referee for a helping me see the need to clarify (and weaken) my original discussion of this point.

10. See Neale (2017: 275-278) for an example of a Grice-inspired theorist who explicitly considers an even weaker constraint on intentions in discussion of speaker meaning. Neale floats the suggestion that the relevant constraint on rational intending is simply that the agent does not believe it is impossible that she $\Phi$ (i.e., she must lacks the belief that it is impossible, rather than positively believing that there is a possibility of success as in (Weak-Constraint)). A theorist who takes the relevant constraint to be (Weak-Constrant) or Neales's even less demanding constraint, might be tempted to respond to the cases offered in the last section by arguing that the speakers can, indeed, rationally have the Gricean intentions as they believe it is possible that that they will 
If (Constraint) were false and (Weak-Constraint) is the only cognitive constraint on intention, we could, for example, easily construct worries for (Consistency). Suppose that I believe I will fail to get lunch tomorrow at Down Home Dim Sum on the far west side of town, but I think there is a remote possibility I will; similarly for getting lunch at Taco Haven on the far east side at exactly that same time. What, if anything, on this view, is to preclude me from rationally forming the intentions to go to Taco Haven tomorrow at noon and the intention to go to Down Home Dim Sum at that same time - a set of intentions that are clearly inconsistent with one another? (Weak-Constraint) on its own seems to me to weak to underwrite (Consistency). Similar worries could equally be raised in connection to (Means-End), as well. But, finally, and much more importantly, I suggest that we ought to hold onto (Constraint) and give up (Grice), since doing so will cost us nothing, as it is easy enough to see the way forward to a suitable replacement for intentions in the characterization of speaker meaning.

Notice that in the foregoing cases-as well as any case in which (Grice) seems to actually apply-a speaker utters what she does with the aim, or with the purpose of getting her audience to entertain something. Equally we can say that in all cases of speaker meaning, the agent (intentionally) produces the evidence that she does for her audience precisely because she aims to get them to entertain something by means of their recognition of her efforts. ${ }^{11}$ I suggest that it is here-with our aims, and communicative purposes - that we should look for the basis of speaker meaning, not with intentions or plans.

The foregoing positive suggestion might initially seem like an odd strategy to pursue, as it requires that it be possible for an agent to intentionally perform an action, while lacking an intention to perform it. But isn't that strange? In our examples above, why can't we just infer that, given that the speaker intentionally sought to get her audience to entertain that such and such, that she acted as she so intended? More generally, if the so-called Simple View of intention and intentional action were correct, we'd be forced to attribute intentions of the (Grice) variety to these agents on the basis of the relevant intentional actions they perform:

(The Simple View): S intentionally $\Phi$ s at $t$ iff, at $t, S$ intends at $t$ to $\Phi$.

As Bratman (1987), Harman (1976), Mele (1992), and other have argued, however, there are good reasons to reject the Simple View.

One familiar reason for rejecting the Simple View pertains to easily foresee-

be understood, or at least do not believe it is impossible that they will be understood. For the reasons given below in the text, I am skeptical that adopting these weaker constraints is the most promising way forward. Thanks to an anonymous referee for a very helpful discussion of this possible response to the dilemma.

11. Here, and in what follows, I use 'want' in the non-appetitive sense (see Goldman 1970). 
able, but unintended, side effects of an agent's acting as she so intended. For example, Harman (1976) gives a case in which a sniper foresees that if she takes the shot we will alert the enemy to our location and endanger us, but she takes the shot anyway as she has her orders. As the sniper knowingly alerted the enemy to our location, she intentionally did so (notice, we'd hold her responsible for having done so). But in such a case, the sniper intentionally alerts the enemy of our location by shooting, though she does not intend to do so, as that is no part of her goal. Or, likewise, consider Bratman's (1987) runner who knowingly and intentionally wears down his sneakers in running the marathon even though it was no part of his intention to do so. ${ }^{12}$ These examples suggest that the Simple View is, perhaps, too simple.

Interestingly, the Simple View also leads to unacceptable results in the case of meaning and communication for related reasons. To illustrate the problem, first notice that in just about any linguistic exchange involving a proper name, a natural kind term, or, for that matter, virtually any noun phrase, there will be numerous descriptive conditions that the speaker will associate with the expression, and will also expect her audience to do so as well. For example, suppose that it is common ground between us that we each associate numerous descriptive conditions with the name 'Aristotle', including being the greatest philosopher of antiquity, being the author of the Nichomachean Ethics, being our friend Jon's favorite philosopher, being the guy that the last colloquium talk was about, among many others. In such a case, were I to sincerely and literally utter (9), I would thereby be stating or literally meaning a proposition concerning Aristotle to the effect that he was Plato's student, but I would also be intentionally providing you with excellent evidence that I believe numerous descriptively enriched propositions, as well:

(9) Aristotle was born in $384 \mathrm{BC}$.

For example, given the common ground between us, I am knowingly, and intentionally, providing you with excellent evidence that I believe, for example, that the guy our last colloquium talk was about was born in $384 \mathrm{BC}$, in addition to what I literally expressed by uttering (9); I might even get you to entertain that proposition, as well. If the Simple View were correct, we would be forced to infer that by uttering (9) I intended you to entertain each of the numerous descriptively enriched propositions that I expect that you might entertain as a result of my utterance. This would, however, be a mistake. In the typical case, we (speakers)

12. Further, as Knobe (2003) points out, our assessments of whether an agent intentionally acted may be tied to our assessment of the normative consequences their action. 
have no such communicative aims; such descriptively enriched propositions are mere communicative by-product of speaker meaning what we did. ${ }^{13}$ One way to see that this communicative descriptively-enriched by-product of our utterances need not be speaker-meant is to consider whether the audience would misunderstand the speaker's utterance if she were to fail to entertain it. For example, suppose that you were to entertain a thought concerning Aristotle to the effect that he was born in $384 \mathrm{BC}$ on the basis of my utterance of (9), but you failed, for whatever reason, to entertain the proposition the guy who our last colloquium talk was about was born in 384 BC. I submit that you need not, for that reason, have misunderstood me. Consequently, we should not take that descriptively loaded proposition to be something I speaker meant even though it is something I am, in some sense, intentionally conveying by uttering (9). More generally, not everything that we knowingly and intentionally convey by our utterances need be speaker meant. ${ }^{14}$

Further if we were to adopt the Simple View, we would be forced to give up on even less demanding principles connecting intention and belief than (Constraint), such as (Weak-Constraint) from above. For example, if the Simple View is correct, even (Weak Constraint) must be rejected. In fact, Bratman (1987) provides a case that shows the Simple View leads to the unacceptable conclusion that an agent might rationally intend to both $\Phi$ and $\Psi$ even though she knows that doing both is impossible.

Bratman's much discussed case concerns an ambidextrous agent, $\mathrm{S}$, who is simultaneously playing two video games, one with each hand. In each game, the goal is to hit on a target on the screen with a missile, but the games are linked in such a way that it is impossible to simultaneously hit the targets on screen A and on screen $B$, and $S$ knows this. If $S$ succeeds in hitting target $A$, we would say that she did so intentionally; likewise for B. If the Simple View were correct this would entail that $S$ acted with the intention of hitting $A$, and also with the intention of hitting $B$. But if one can rationally intend to $F$ and rationally intend to $G$, only if one can rationally intend to $F$ and $G$, we should conclude that $S$ rationally intended both to hit A and to hit B. Notice that the Simple View drives us to attribute an intention to do something (i.e., to hit both targets) that the agent knows to be impossible to achieve; hence, the Simple View would require us to give up

13. I borrow the phrase 'communicative by-product' from Buchanan (2014b) in which similar considerations are used as part of an argument against the view that we assert (Soames 2002; 2005; 2008) or semantically express (Glezakos 2011) descriptively enriched propositions in typical utterances involving proper names.

14. One potential consequence of these considerations is that a speaker can be held responsible, or accountable, for 'pragmatically conveyed' content that she did not, speaker mean-literally, or indirectly as in a case of implicature. 
even (Weak Constraint). But rather than accept that (Weak Constraint), or much less (Constraint), we should follow Bratman and hold that $S$, despite acting intentionally, acted with neither the intention to hit A or the intention to hit B. ${ }^{15}$

If we give up the Simple View, how then can we account for the intentional actions of, for example, our quarterback, or Bratman's video game-player? If these agent's aren't acting on an intention to do just what they intentionally do, then what exactly are they doing? According to Bratman, we might say that the quarterback is acting on a guiding desire - a desire that not only motivates the agent to act, but also-like an intention-helps to initiate and guide behavior. ${ }^{16}$ In effect, Bratman's guiding desires are conduct initiating and controlling proattitudes that are just like intentions except for not being subject to rationality constraints such as (Consistency) or (Means-End). Though Bratman himself does not conceive of matters in this way, we might think of intentions, proper, as simply a sub-species of our guiding desires - namely, intentions are those of our guiding desires that are backed with an appropriately high confidence in success (or at least of non-failure) to be connected to the agent's outright beliefs in the ways needed for principles such as (Consistency) and (Means-End) to apply. ${ }^{17}$ If talk of desires is ultimately reducible to talk of preferences, we might even go on to identify the relevant states as credence/preference pairs that cause, and rationalize, the relevant action.

Understood as such, guiding desires are both distinct from, but also more basic than our intentions. On this suggestion, even those acts of meaning in which it is appropriate to speak of the agent's communicative intentions are ones in

15. See Bratman (1987: 116-126) for replies to various doubts and responses one might make to the case. See Di Nucci (2010) and McCann (1991) for further discussion.

16. In his attempt to resuscitate the Simple View, McCann (1991) argues that if Bratman's guiding desires can initiate and guide action, then they just are intentions. Roughly put, McCann thinks that if guiding desires have exactly the same functional role as intentions, then they are intentions. Though the conditional claim is true, its antecedent is only as plausible as the denial of (Constraint) above, since if that constraint holds then at least one important aspect of the functional role of intentions are their connections with our beliefs, and this is not shared by Bratman's guiding desires. For an important related discussion see Mele (1992: Chapter 8).

17. On the suggestion here, an agent who $\Phi$ s on the basis of a guiding desire to do so thereby $\Phi s$ intentionally; guiding desires are themselves sufficient for intentional action. Bratman (1987) seems to disagree, holding that in order for an agent to intentionally $\Phi$ she must either (a) act on an intention to $\Phi$, or else (b) act on some other intention $\Psi$ that is appropriately related to her $\Phi$ ing. The rough idea of Bratman's 'single phenomenon' account is that intentional actions are either themselves intended, or else somehow embedded in an intention or plan in an appropriate way. While I have some sympathy towards this suggestion with regard to cases of intentional, yet unintended side effects, the proposal is more generally, an unhappy halfway house to the more radical suggestion I offer in the text. The moral to draw from the case against the Simple View is that no intentions are required for intentional action. Similarly, Mele (1992) suggests that we replace the Simple View with a disjunctive account on which either the agent must intend to $\Phi$ or else intend to try to $\Phi$ does not, by my lights, go far enough, though making the case against this will have to wait for another occasion. 
which she still has the communicative wants, or aims, in the foregoing sense. Crucially, however, there are also cases in which a speaker who means that $p$ has only the latter.

If we were required to find some variety of cognitive state, other than an intention, that might causally back, and serve to rationalize, our acts of speaker meaning, Bratman's guiding desires would do just fine. There are, however, theorists in the tradition of Anscombe who might be happy to countenance our talk of a speaker acting with such and such communicative aim, or goal, or desire, but who would insist that we not conceive of these as something separable from the speaker's intentional communicative act itself-much less as antecedently given mental states that lie behind, or cause, those actions. We need not settle these foundational debates in the theory of action here. Suffice it to say for now, the key to understanding how to correct the Gricean account of meaning and communication is to look to the aims, goals, and wants with which we speak. The basis of meaning is to be found here, not with intentions.

Before closing, it is important to note some potential implications of the foregoing revision to (Grice) for broader, foundational issues in the philosophy of language. Historically, one of the primary reasons for interest in the analysis of speaker meaning is its potential role in a reduction of the semantic to the psychological. Schiffer (1982), Loar (1981), and other "Gricean" reductionists, have sought to explicate public-language semantic properties - including the contextinvariant meaning of sentence-types -in terms of standardized, or conventionalized, regularities linking types of utterances and types of communicative intentions. The general idea behind this reductivist strategy was that an expression E's having a meaning property $\mathrm{M}$ among a particular group of speakers is, as Schiffer once put it,

a matter of there being a regularity of communicative behavior with respect to $[\mathrm{E}]$, or more commonly, with respect to the constituents and structure of [E], such that were one to utter [E] in conformity with these regularities, one would thereby mean a proposition of a certain type. (Schiffer 1982)

Further, following a suggestion by Strawson (1964), these theorists sought to explicate speech-act theoretic notions such as suggesting, promising, commanding, referring, and the like, in terms of speaker meaning, and when needed regularities (perhaps conventional) thereof. Insofar as one is sympathetic to these reductive projects (as I am), one should also be interested in the suggested revision to (Grice) as it will have important downstream effects on the details of one's favored foundational account of linguistic/expression meaning and one's account of speech acts, including our assertoric speech acts (saying, stating, etc.) 
and our referential intentions. ${ }^{18}$ If the foregoing discussion is on the right track, the analysis of speech acts, linguistic meaning, or communication need not traffic in intentions of the Gricean variety. The proposed shift from communicative intentions will not, however, change the general shape of the reductive project envisioned by Schiffer and Loar. In order for the reduction of the semantic to the psychological to be carried off, we must be able to analyze speaker meaning without essential appeal to public language semantic properties in the content of utterer's meaning-related mental states. It should be clear that the prospects for these grander reductionist projects are unaffected by our shift from communicative intentions to communicative aims, desires, and goals.

Many of the issues I have discussed concerning cognitive constraints on intention, as well as the relationship between intentions and intentional action, will likely already be familiar to those working in action theory. I do not, of course, take myself to have settled any of these complex, longstanding issues in the theory of action (though I do think the proposal I've made regarding the relationship between intentions, guiding desires, and intentional action offers some advantages over Bratman's conception of these notions and their interrelations). Rather, my aim has been to show that those of us who take the notion of speaker meaning to be of central importance in the theory of meaning, communication, and pragmatics can gain important insights by looking to the work of our colleagues in action theory. As Grice correctly pointed out, a speaker means something by doing something, this doing itself being a species of intentional action. It does not follow from this, however, that speaker meaning must be analyzed in terms of intentions. Indeed, if intentions are what many, if not most, action theorists take them to be, Grice, and those who've followed him, are incorrect; intention is not the basis of speaker meaning.

18. Consider one more specific consequence of giving up (Grice). In Buchanan (2014a), I argued that in typical cases of particularized conversational implicatures (think, for example, of Grice's much discussed letter of recommendation case), there will be no unique proposition implicated. Roughly put, my reasons for this claim were that (i) conversational implicature is a species of speaker meaning), (ii) a rational speaker's meaning that $p$ by an utterance requires her intending and, hence believing that her audience will entertain that $p$ on the basis of her efforts, but, (iii) given the multiplicity of non-equivalent candidate propositions implicated, the speaker cannot rationally believe her audience will get any one of the candidates to the exclusion of the others. If, as I have argued, a speaker might rationally mean that $p$ while actively believing her audience won't entertain that proposition, (ii) must be rejected, and with it the more sweeping claims about the non-specificity of conversational implicature based on (ii). But, although the original argument I gave fails for the reason just given, we can, I think, reach the same conclusion in a slightly different way. In the relevant range of cases, we should ask if we would take the speaker to have failed at doing something she was aiming at, or trying to bring about, by her speech act, should her hearer have failed to entertain this, or that, specific candidate conversational implicature? If the answer is ' $\mathrm{No}^{\prime}$, the point I sought to make about the indeterminacy and non-specificity of particularized implicatures stands. Thanks to Neil Sinhababu for discussion of this point. 


\section{Acknowledgements}

I'd like to thank David Beaver, Jonathan Dancy, Josh Dever, Sinan Dogramaci, Jonathan Drake, Matt Evans, Amelia Kahn, Megan Hyska, Gary Ostertag, Henry Schiller, Neil Sinhababu, David Sosa, Bronwyn Stippa, and the students from my graduate course on Intentional Action in Spring 2015, for invaluable comments and feedback on this material.

\section{References}

Anscombe, Elizabeth (1963). Intention (2nd ed.). Blackwell.

Avramides, Anita (2017). Abiding Intentions. In G. Ostertag (Ed.), Meaning and Other Things (343-364). Oxford University Press.

Bratman, Michael (1987). Intention, Plans, and Practical Reason. Harvard University Press.

Buchanan, Ray (2014a). Conversational Implicature, Communicative Intentions, and Content. Canadian Journal of Philosophy, 43(5), 720-740.

Buchanan, Ray (2014b). Names, Descriptions, and Assertion. In T. Hung (Ed.), Communicative Action: Selected Papers of the IEAS Conference on Language and Action (3-15). Springer,

Di Nucci, Ezio (2010). Rational Constraints and the Simple View. Analysis, 70(3), 481-486.

García-Carpintero, Manuel (2016). Implied Assertion. Polish Journal of Philosophy, 10(1), $13-49$.

Grice, Paul (1957). Meaning. The Philosophical Review, 66(3), 377-388.

Grice, Paul (1969). Utterer's Meaning and Intentions. The Philosophical Review, 78(2), 14777 .

Grice, Paul (1971). Intention and Uncertainty. Proceedings of the British Academy, 57, 263279.

Grice, Paul (1989). Studies in the Way of Words. Harvard University Press.

Goldman, Alvin (1970). A Theory of Human Action. Princeton University Press.

Glezakos, Stavroula (2011). The Propositions We Assert. Acta Analytica, 26(2), 165-173.

Harman, Gilbert (1976). Practical Reasoning. The Review of Metaphysics, 29(3), 431-463. Reprinted Mele (1997), 149-177.

Harman, Gilbert (1986). Willing and Intending. In R. E. Grandy and R. Warner (Eds.), Philosophical Grounds of Rationality (363-380). Oxford University Press.

Knobe, Joshua (2003). Intentional Action and Side Effects in Ordinary Language. Analysis, 63(279), 190-194.

Loar, Brian (1981). Mind and Meaning. Cambridge University Press.

Lycan, William (2008). Philosophy of Language: A Contemporary Introduction. Routledge.

McCann, Hugh (1991). Settled Objectives and Rational Constraints. American Philosophical Quarterly, 28(1), 25-36. Reprinted in Mele (1997), 204-222.

Mele, Alfred (1992). Springs of Action. Oxford University Press.

Mele, Alfred (1997). The Philosophy of Action. Oxford University Press.

Neale, Stephen (2017). Silent Reference. In G. Ostertag (Ed.), Meaning and Other Things (229-343). Oxford University Press.

Ostertag, Gary (2017). Meaning and Other Things. Oxford University Press. 
Ross, Jacob (2009). How to Be a Cognitivist about Practical Reason. Oxford Studies in Metaethics (Vol. 4, 243-281). Oxford University Press.

Schiffer, Stephen (1972). Meaning. Oxford University Press.

Schiffer, Stephen (1982). Intention-Based Semantics. Notre Dame Journal of Formal Logic, 23(2), 119-156.

Schiffer, Stephen (1987). Remnants of Meaning. MIT Press.

Schiffer, Stephen (2017). Gricean Semantics and Reference: Responses to Anita Avramides, Stephen Neale, and Kent Bach (2017). In G. Ostertag (Ed.), Meaning and Other Things (493-529). Oxford University Press.

Sinhababu, Neil (2013). The Desire-Belief Account of Intention Explains Everything. Noûs, $47(4), 680-696$.

Soames. Scott (2002). Beyond Rigidity: The Unfinished Semantic Agenda of Naming and Necessity. Oxford University Press.

Soames, Scott (2005). Naming and Asserting. In Z. Szabo (Ed.), Semantics versus Pragmatics (356-382). Oxford University Press.

Soames, Scott (2008). The Gap between Meaning and Assertion: Why What We Literally Say Often Differs from What Our Words Literally Mean. In Philosophical Essays, Volume 1: Natural Language, What It Means \& How We Use It (Vol. 1, 278-297). Princeton University Press.

Strawson, Peter (1964). Intention and Convention in Speech Acts. The Philosophical Review, 73(4), 439-460.

Sturgeon, Scott (2008). Reason and the Grain of Belief, Noûs, 42(1), 139-165

Velleman, David (1989). Practical Reflection. Princeton University Press. 